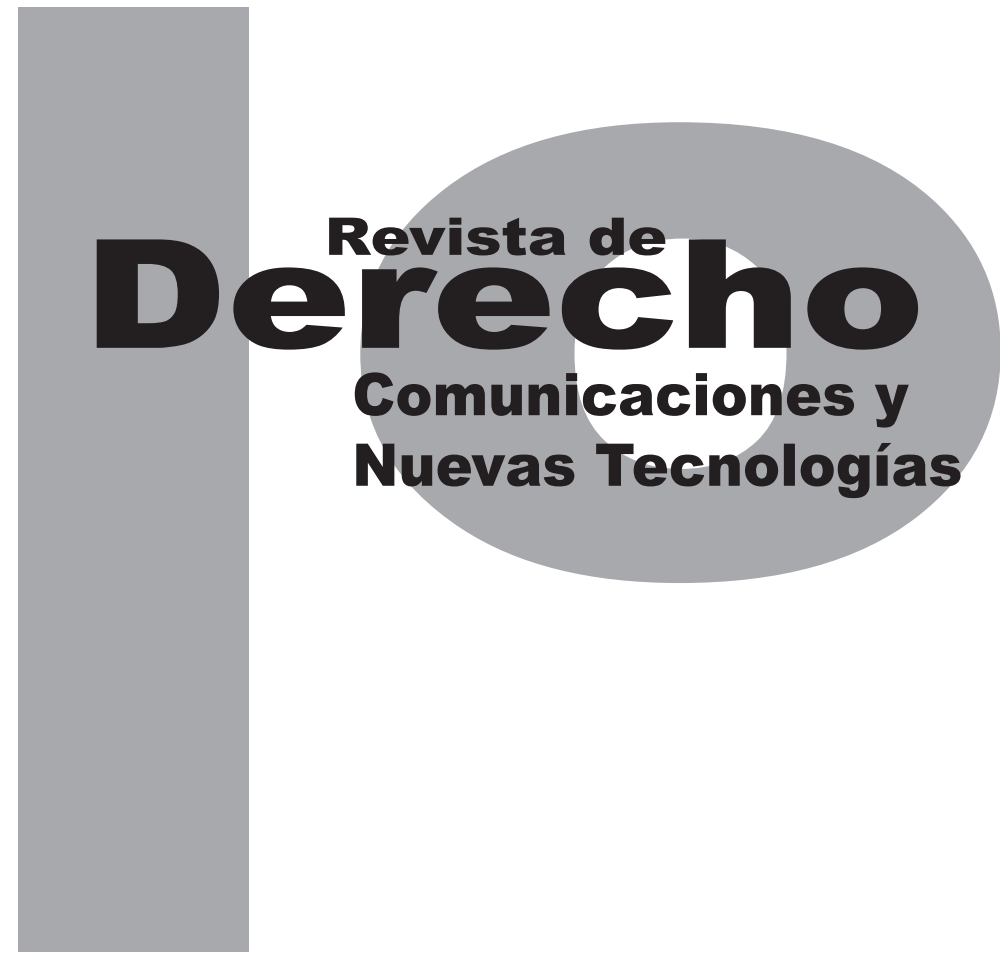

\title{
LOS TÉRMINOS Y CONDICIONES COMO MITIGANTES DE RIESGOS CONTRACTUALES PARA TRANSACCIONES EN INTERNET: UNA MIRADA DESDE LOS PRODUCTOS BANCARIOS Y EL E-TRADING
}

\author{
Guillermo Betancourt CARdona
}

Artículo corto

Universidad de los Andes

Facultad de Derecho

Revista de Derecho, Comunicaciones y Nuevas Tecnologías

No.11, Enero - Junio de 2014. ISSN 1909-7786 


\title{
Los términos y condiciones como mitigantes de riesgos contractuales para transacciones en internet: una mirada desde los productos bancarios y el $e$-trading
}

\section{Resumen}

Con el creciente uso de las tecnologías de la información para la realización de toda clase de transacciones y operaciones económicas en internet, y el aparejado desarrollo de la delincuencia informática, aunado a fallas en los equipos o programas, se hace indispensable analizar si la regulación convencional empleada actualmente para regular dichas transacciones cumple con una función ordenadora o, por el contrario, satisface apenas un requisito formal.

Palabras clave: Derecho y tecnología, protección al consumidor, contratos, términos y condiciones, responsabilidad.

\section{Terms and conditions as contracting risk mitigating factor in internet transactions: A view from banking products and e-trading}

\begin{abstract}
With the growing usage of information technologies for all sorts of online transactions and operations, and the coupled development of cybercrime, along with service failures, it is of the most importance to analyze if the current contractual regulation for those transactions complies with a commanding function or, on the contrary, it is an instrument for a formal compliance.
\end{abstract}

Keywords: Law and technology, customer protection, contracts, terms and conditions, liability.

\section{Os termos e condições como mitigantes de riscos contratuais para transações na internet: um olhar desde os produtos bancários e o e-trading}

\section{Resumo}

Com o crescente uso das tecnologias da informação para a realização de todo tipo de transações e operações econômicas na internet, e o também desenvolvimento da delinquência informática, unido com as falhas nos equipamentos ou programas, é indispensável analisar se a regulação convencional empregada atualmente para controlar ditas transações cumpre com uma função ordenadora ou, pelo contrário, satisfaz apenas um requisito formal.

Palavras-chave: Direito e tecnologia, proteção ao consumidor, contratos, termos e condições, responsabilidade. 


\section{SUMARIO}

Introducción - I. EL PANORAMA ACTUAL DE LA REGULACIÓN - II. NORMAS VIGENTES SOBRE SEGURIDAD DE LA INFORMACIÓN - III. LA DOCUMENTACIÓN DE LOS TÉRMINOS Y CONDICIONES DE USO Y SERVICIO - A. Caracterización de los términos y condiciones - B. Regulación especial de términos y condiciones - C. Concepciones resultantes - D. Acuerdo principal, ¿accesorio o coaligado? - E. El caso especial del enrutamiento de órdenes - F. Propuesta sobre la naturaleza jurídica de los términos y condiciones y conclusión - IV. PERSPECTIVA DE RESPONSABILIDAD CIVIL - A. Imputabilidad - B. Daño - C. Relación de causalidad - D. Hecho dañoso - E. Deberes jurídicos de fuente legal a cargo de las entidades vigiladas - F. Deberes jurídicos de fuente legal a cargo de los consumidores financieros - V.CONCLUSIONES - Referencias 


\title{
Los términos y condiciones como mitigantes de riesgos contractuales para transacciones en internet: una mirada desde los productos bancarios y el e-trading ${ }^{1}$
}

\author{
Guillermo Betancourt Cardona²
}

Introducción

Sin duda, en una sociedad altamente dependiente de la tecnología para su desarrollo, en la que incluso el Estado es el primer impulsor del uso de medios y herramientas tecnológicas, la seguridad de la información termina permeando la mayor cantidad de capas de la interacción económica, en los sectores que se apalancan en estas nuevas plataformas.

Cómo citar este artículo: Betancourt Cardona, E. (Junio, 2014). Los términos y condiciones como mitigantes de riesgos contractuales para transacciones en internet: una mirada desde los productos bancarios y el e-trading. Revista de Derecho, Comunicaciones y Nuevas Tecnología, 11.

2 Abogado de la Universidad San Buenaventura de Cartagena (2005). Especialista en Derecho del Mercado de Capitales de la Pontificia Universidad Javeriana (2008) y en Derecho Comercial de la Universidad de los Andes (2011), estudiante del diplomado de Operación Bursátil de Asobursátiles (febrero - junio 2014) y candidato admitido a la Maestría en Derecho Privado de la Universidad de los Andes. Ha sido profesor invitado a la Especialización en Derecho de la Empresa de la Universidad del Rosario, y se desempeña actualmente como coordinador jurídico y secretario general del grupo financiero Old Mutual - Skandia en Colombia. Correo electrónico: gbetacard83@gmail.com
En ese sentido, como bien lo indica Mariliana Rico en su texto Derecho de las nuevas tecnologías, "ya no resulta extraño utilizar conceptos tales como internet, globalización, economía digital, sociedad de la información, junto al agregado del adjetivo electrónico a los documentos, los negocios, el comercio e inclusive al gobierno", todo lo cual, podría decirse, hace parte de los bienes de la llamada "sociedad de la información", en la que habitamos como producto de la tecnificación de nuestros procesos, relaciones, e incluso de nuestros medios de difusión de pensamiento. Esto llega, incluso, hasta las mismas redes sociales, a través de las cuales se crea un mundo paralelo de interrelaciones que, cada vez con más claridad, afectan el mundo real en el que vivimos.

Esta situación es tan patente en el caso colombiano, que la Ley 1341 de 2009, por la cual se definen principios y conceptos sobre la sociedad de la información y la organización de las Tecnologías de la Información y las Comunicaciones, establece que “[...] las entidades públicas debe- 
rán adoptar todas las medidas necesarias para garantizar el máximo aprovechamiento de las Tecnologías de la Información y las Comunicaciones en el desarrollo de sus funciones".

En adelante, sendas piezas normativas y regulatorias han sido expedidas para darle vida a esta iniciativa, que persigue facilitar a los países en vías de desarrollo dar "un salto en [...] la [...] evolución económica, política, social y cultural, disminuyendo la brecha que los separa de los países desarrollados [...]".3

Unido a lo anterior, el documento Conpes 3650 del 15 de marzo de 2010 declara de importancia estructural la implementación de la estrategia de Gobierno en Línea en Colombia.

Con los planteamientos previos, es evidente para cualquier lector la apuesta del Estado en la tecnificación de sus relaciones con los administrados, con el fin de hacer más fácil, cercano y eficiente el gobierno de los mismos.

En esta sociedad de la información, el sector financiero y bursátil, en general, es uno de los más elaborados en sus desarrollos y ofertas en torno a la tecnología como mecanismo para facilitar la interacción con sus consumidores financieros.

En efecto, basta tan solo con revisar la página web de cualquier entidad bancaria o bursátil para encontrar una fecunda variedad de dispositivos, mecanismos y aplicaciones que facilitan

3 http://wsp.presidencia.gov.co/Normativa/DAPRE/Paginas/GobiernoEnLinea.aspx al consumidor la operación y uso de los productos y servicios ofrecidos por las entidades vigiladas por la Superintendencia Financiera de Colombia (en adelante, las "entidades vigiladas"). ${ }^{4}$

No obstante, no se trata de una oferta libre, debido a los riesgos que le son inherentes, considerando el alto uso de estos medios tecnológicos como mecanismos para la concreción de relaciones económicas.

De hecho, con solo revisar las cifras de delincuencia informática se entiende que el imaginario criminal también es plenamente consciente del nuevo escenario que ha surgido para sus fechorías; "[t]anto que Colombia es, actualmente, el tercer país en Latinoamérica donde más se cometen $[. .$.$] delitos informáticos [. .]. "{ }^{5}$

Aunque tal vez más preocupante que el índice de criminalidad, resultan las condiciones de absoluto dominio y falta de claridad en que se contratan los servicios informáticos asociados a productos bancarios o de e-trading por parte de los consumidores financieros, quienes no dimensionan la importancia del impacto pecuniario de un evento de responsabilidad, relacionado con la seguridad de la información de aquellos productos.

En efecto, es muy común que se inicie la utilización de servicios electrónicos asociados a productos bancarios o del e-trading sin hacer

\footnotetext{
4 Bajo este rubro, igualmente, se incluyen las entidades oferentes de productos o servicios bancarios y de e-trading.

5 http://www.elpais.com.co/elpais/judicial/noticias/colombia-cifras-delitos-informaticos-van-aumento
} 
un análisis somero, cuando menos, de los términos y condiciones convencionales a los que un consumidor financiero se adhiere cada vez que recurre a estos medios tecnológicos para realizar transacciones de carácter monetario y no monetario. ${ }^{6}$

La importancia de esta juiciosa lectura puede ser de capital importancia al momento de decidir usar o no el servicio tecnológico del producto bancario o bursátil, dado que en las condiciones convencionales de uso - de antaño-, las entidades vigiladas establecieron toda clase de cláusulas que, hoy en día, bajo la regencia de la Ley 1328 de $2009,{ }^{7}$ son consideradas abusivas, con ejemplificaciones del legislador y el regulador, que en no más de una ocasión devienen de experiencias negativas en el uso de estos medios.

De ahí la importancia de analizar, a través de este artículo corto, en qué condiciones contractuales se acuerdan los servicios electrónicos de productos bancarios y de e-trading, y el nivel de

6 De conformidad con el numeral 2.8 del capítulo XII, título I, de la Circular Básica Jurídica de la Superintendencia Financiera de Colombia, el cual regula la prestación de servicios financieros y bursátiles a través de canales electrónicos, entre otros, constituyen operaciones monetarias y no monetarias las siguientes:

2.8.1 Operaciones no monetarias

Son las acciones a través de las cuales se desarrollan, ejecutan o materializan los productos o servicios que prestan las entidades a sus clientes o usuarios y que no conllevan movimiento, manejo o transferencia de dinero.

2.8.2 Operaciones monetarias

Son las acciones que implican o conllevan movimiento, manejo o transferencia de dinero.

7 Por la cual se dictan normas en materia financiera, de seguros, del mercado de valores y otras disposiciones (también conocida como "reforma financiera"). seguridad de los mismos frente a abusos institucionales 0 , incluso, el nivel de seguridad que los mismos pueden ofrecer frente a eventos de responsabilidad civil en el mundo electrónico.

\section{EL PANORAMA ACTUAL DE LA REGULACIÓN}

La Superintendencia Financiera de Colombia, como organismo técnico a través del cual el presidente de la República ejerce la inspección, vigilancia y control sobre las personas que realicen actividades financieras, bursátiles, aseguradoras, y cualquier otra relacionada con el manejo, aprovechamiento o inversión de recursos captados del público, se ha asegurado de fijar reglas técnicas que garanticen la adecuada seguridad de la información de los servicios y productos que hacen parte de la oferta tecnológica de estas entidades oferentes de productos bancarios o de e-trading, y en general de las entidades vigiladas.

El motivo de ello es sencillo: bajo los esquemas de oferta electrónica de productos bancarios y de e-trading, se excluye de la ecuación a las oficinas físicas como recinto de acceso tradicional a dichos productos - considerada más segura-, permitiendo "[...] al cliente acceder directamente a su banco desde fuera", como se desprende del texto Contratos bancarios. Su significación en América Latina, de Sergio Rodríguez Azuero (2011). Y anota este mismo autor, al discurrir sobre la banca a distancia o home banking -como se le ha venido a denominar a esta evolución tecnológica de los servicios financieros-, que la 
gran ventaja que ofrece sobre otros esquemas de relacionamiento es que se encuentra disponible los 365 días del año, las 24 horas del día. $Y$ resulta cierta esta afirmación.

Paralelo al progreso tecnológico y regulatorio, pulula también la delincuencia, migrando del mundo de las oficinas físicas, a los escenarios cibernéticos, situación que ha llevado a las autoridades de todos los sectores, y especialmente a la Superintendencia Financiera de Colombia, a expedir piezas regulatorias que tiendan a establecer un marco normativo que asegure, no solo el aspecto técnico, sino también la protección al consumidor. Esto por cuanto la regulación era hasta hace muy poco desprolija, expidiéndose normas aisladas sobre seguridad de la información para la operación de redes de cajeros y datáfonos, entre otros.

En este auge tecnológico, el salto hacia una regulación robusta fue claro con la expedición de la Circular Externa 042 de 2007, con la que se adicionó el capítulo XII, título I, a la Circular Básica Jurídica de la Superintendencia Financiera -en adelante, capítulo XII-, como se verá en el siguiente acápite.

\section{NORMAS VIGENTES SOBRE SEGURIDAD DE LA INFORMACIÓN}

En el precitado capítulo XII reposan las instrucciones relativas a los requerimientos mínimos de seguridad y calidad en el manejo de información a través de medios y canales de distribución de productos y servicios para clientes y usuarios, que deben observar las entidades vigiladas en general. Incluidas sus modificaciones recientes, el capítulo XII contempla disposiciones relativas a obligaciones generales, seguridad y calidad, tercerización - outsourcing, documentación, divulgación de información y obligaciones adicionales por tipo de canal.

Ante este derrotero normativo, y para los fines de este documento, sea lo primero analizar los aspectos técnicos en su ser y hacer para llegar a las conclusiones e impactos legales derivados de los mismos.

Así las cosas, con sujeción al anterior orden, a continuación se mencionarán los canales e instrumentos a través de los cuales las entidades bancarias y bursátiles, entre otras, estructuran esta nueva puerta de acceso a sus productos y servicios.

En efecto, el numeral 2.3 del capítulo XII dispone los siguientes canales para la distribución de los servicios financieros de las entidades vigiladas:

a) Oficinas

b) Cajeros automáticos (ATM)

c) Receptores de cheques

d) Receptores de dinero en efectivo

e) POS (incluye PIN Pad)

f) Sistemas de audio respuesta (IVR) 
g) Centro de atención telefónica (call center, contact center)

h) Sistemas de acceso remoto para clientes (RAS)

i) Internet

j) Banca móvil

Considerando que las oficinas son el canal tradicional de las entidades vigiladas para la oferta y distribución de sus productos y servicios, el foco de este documento se alejará de las mismas. Lo anterior, teniendo en cuenta que el análisis de los riesgos inherentes a su naturaleza, si bien evoluciona conforme lo hace el imaginario criminal, se encuentra suficientemente analizado.

En este sentido, el foco de este documento serán los riesgos derivados del uso de los canales basados en internet. Pero no cualquier riesgo: en la investigación de este artículo se encontraron dos grupos principales de riesgos que afectan este canal; unos de carácter técnico, y otros de carácter contractual. Según la doctrina internacional, los principales riesgos técnicos que afronta la seguridad de la información son el malware, los hackers y el phishing. El maIware (malicious software, por sus siglas en inglés), es entendido como aquel que se ejecuta en un sistema sin conocimiento o autorización del usuario o propietario; se desprenden de este múltiples figuras de denominación más popular como los virus, gusanos, troyanos, spyware, adware, entre otros. Por su parte, los hackers vienen a constituir profesionales o técnicos con profundos conocimientos tecnológicos, empleados para acceder abusivamente sistemas electrónicos. Finalmente, el phishing es un abuso informático diseñado para acceder a información confidencial sin autorización (Écija, capítulo VIII).

Se encuentra, entonces, que estos riesgos técnicos por sí mismos tienen la entidad suficiente para generar una afectación patrimonial para los usuarios de internet u otros canales. Sin embargo, la responsabilidad en estos casos puede estar ubicada en la entidad vigilada, si no implementó mecanismos de seguridad informática adecuados para prevenir estas infracciones; o bien puede atribuirse al criminal perpetrador, lo cual conllevaría la intervención de autoridades penales para el establecimiento de una eventual responsabilidad de este corte.

Por otra parte, los riesgos contractuales -segundo set de riesgos identificados- afectan igualmente al consumidor desde una perspectiva patrimonial; sin embargo, aquí el abuso, contravención o ejecución proviene, normalmente, de la entidad vigilada, que dispone unilateralmente términos y condiciones en que prestará servicios a través de canales de internet, sin lugar a discusión o negociación alguna.

Este documento se enfocará en los riesgos de orden contractual. 


\section{LA DOCUMENTACIÓN DE LOS TÉRMINOS Y CONDICIONES DE USO Y SERVICIO}

En la actualidad, el capítulo XII dispone como obligación de documentación de las entidades vigiladas, la siguiente:

3.3.1. Conservar todos los soportes y documentos donde se hayan establecido los compromisos, tanto de las entidades como de sus clientes y las condiciones bajo las cuales estas prestarán sus servicios.

Hasta antes de la expedición inicial del capítulo XII, la documentación de este tipo de acuerdos y compromisos se plasmaba normalmente en los denominados "términos y condiciones de uso".

Estos documentos, de amplia tradición en el derecho anglosajón, principalmente consuetudinario, y cada vez más escriturario, también son conocidos como "términos de uso" o "términos de servicios" (TOS, TOU, por sus abreviaturas en inglés), y son considerados acuerdos, cuyo uso principal se orienta al establecimiento de reglas convencionales respecto del uso de páginas web y proveeduría de servicios de internet.

En efecto, al revisar la historia de su establecimiento en los Estados Unidos, encontramos que sus primeros usos provienen de la creación de la infraestructura jurídica de la industria tecnológica, comenzando por clickwraps, installwraps, browsewraps, migrando hoy en día a términos de uso para la navegación de páginas web y redes sociales, entre otros, y participando estos "acuerdos" del carácter unilateral y atípico de que gozan en nuestros sistemas jurídicos (Rustad y Onufrio, 2012).

Por su parte, el legislador español, apegado más al texto escrito de la ley, establece -al referirse a las condiciones generales de la contratación, y en particular a las cláusulas predispuestasen su Ley de Condiciones Generales de la Contratación, que:

son condiciones generales de la contratación las cláusulas predispuestas cuya incorporación al contrato sea impuesta por una de las partes, con independencia de la autoría material de las mismas, de su apariencia externa, de su extensión y de cualesquiera otras circunstancias habiendo sido redactadas con la finalidad de ser incorporadas a una pluralidad de contratos.

Empero, la experiencia internacional enseña que sistemas como el español y el argentino, al regular lo que estas denominan las condiciones contractuales generales, establece a cargo del oferente o empresario obligaciones de información previa, concomitante y posterior a la concreción de negocios a través de canales de internet.

Tal y como se estableció, el uso de estos documentos de talante contractual no ha sido ajeno al mundo jurídico colombiano, y, de hecho, en la mayoría de casos su aplicación ha estado orientada a gobernar las relaciones que surgen en el marco de actividades de comercio electrónico, muy a pesar de que el mismo no se encuentra consagrado en estricto sentido en el sistema jurídico colombiano, como figura autónoma, me- 
recida por su importancia en el marco de estos procesos contractuales.

Algo similar se encuentra en nuestra Ley 1480 de $2011,{ }^{8}$ en la que, al establecer las condiciones negociales generales y de los contratos de adhesión, dispone que debe existir información suficiente; condiciones generales del contrato que deben ser concretas, claras y completas, legibles a simple vista, y no incluir espacios en blanco.

No obstante, la regulación no profundiza en estos aspectos que, ciertamente, dejan abierto el espacio para la interpretación de los particulares, la cual, si bien es proconsumidor, no asegura que estos sean protegidos en el diseño de este tipo de soluciones contractuales, pues a quien predispone las cláusulas lo gobiernan intereses sustancialmente diferentes de aquellos que profesan los consumidores.

\section{A. Caracterización de los términos $y$ condiciones}

Ser un documento de adhesión puede ser su característica más importante, allende de su contenido, pues al igual que los contratos y acuerdos de productos financieros y bursátiles que en general se suscriben con entidades vigiladas, los mismos no son objeto de negociación previa entre las partes, limitándose el consumidor financiero a bien aceptarlos en su integridad, o rechazarlos en el mismo sentido, no existiendo un punto medio en este estadio del análisis.

8 Por la cual se expide el Estatuto del Consumidor.
En efecto, ha dicho la Superintendencia Financiera que el contrato de adhesión o contratotipo -o de condiciones generales- es "aquel en que las cláusulas son dispuestas por uno de los contratantes de manera que la contraparte no pueda modificarlas ni hacer cosa distinta que aceptarlas o rechazarlas" (negrillas y subrayado por fuera del texto) (Concepto 2007001302001 del 23 de febrero de 2007, Superintendencia Financiera de Colombia).

Sobre este punto, la doctrina argentina ha manifestado que, en su entendimiento, un contrato por adhesión y condiciones generales de contratación constituyen un mismo acuerdo, pues el contrayente débil de la relación solo tiene la opción de adherirse, sin más, a las cláusulas predispuestas en su totalidad, o abstenerse de contratar (Farina, 2011).

Pero si bien se trata de un documento de carácter adhesivo, ¿cuál es su naturaleza jurídica de cara a las normas de seguridad de la información citadas en la precedencia?

Para dilucidar este interrogante, retomamos la cita del numeral 3.3.1 del capítulo XII, el cual reza tímidamente que es obligación de todas las entidades vigiladas oferentes de servicios electrónicos documentar y conservar los "[...] compromisos, tanto de las entidades como de sus clientes y las condiciones bajo las cuales estas prestarán [...] los [...] servicios" a los que se refiere el mencionado capítulo, y no asigna un tipo contractual específico para este acuerdo.

Así las cosas, para iniciar, se podría concluir a lo menos que se trata de un contrato o convenio 
de carácter atípico, puesto que claramente existe "la posibilidad de usar moldes contractuales no regulados por el ordenamiento jurídico [...] y eso [...] es lo que ha dado lugar a hablar de la 'flexibilidad' del tipo contractual" (Arrubla, 2008, p. 29).

Así las cosas, y siendo que los términos y condiciones como una figura autónoma carecen de consagración en los ordenamientos civil y comercial, es menester descartar la regulación especial del sector bancario y bursátil a fin de determinar si, en la misma, existen referencias a dichos documentos.

\section{B. Regulación especial de términos $y$ condiciones}

El Estatuto Orgánico del Sistema Financiero (Decreto - Ley 663 de 1993) recurre a la frase "términos y condiciones" para referirse, en muchas ocasiones, a las disposiciones concretas en que el Gobierno nacional fue habilitado para reglamentar dicho estatuto, así como para referirse a términos y condiciones de otras normas, pero no necesariamente con una perspectiva contractual.

Por su parte, en la Ley 1328 de 2009, también se encuentran referencias a la frase "términos y condiciones", siendo de importancia su artículo sexto, en el que establece como práctica de autoprotección de los consumidores financieros “d) Revisar los términos y condiciones del respectivo contrato y sus anexos, así como conservar las copias que se le suministren de dichos documentos".
No obstante, al culminar la lectura del mencionado artículo, el legislador, con un matiz proteccionista pero a la vez contradictorio, consagra una excepción a las prácticas de autoprotección del consumidor financiero, que crea un incentivo negativo para que estos desconozcan su debida diligencia mínima como consumidores de productos y servicios, con un nivel importante de complejidad en su estructuración legal y contractual. Ciertamente, el parágrafo primero del mencionado artículo contempla que "el no ejercicio de las prácticas de protección propia por parte de los consumidores financieros no implica la pérdida o desconocimiento de los derechos que le son propios ante las entidades vigiladas y las autoridades competentes". Si se analiza esta disposición bajo una óptica de responsabilidad civil, pareciera poderse elucidar del texto que, no obstante la omisión del consumidor -lo cual podría ser considerado como una especie de culpa o hecho propio eximente de responsabilidad para su contraparte-, este no se desposee de ninguna prerrogativa de protección actuando casi como una especie de premio en derechos, muy a pesar de haber desatendido su debida diligencia mínima como consumidor.

Paralelamente, el legislador erigió como obligación de las entidades vigiladas “f) Elaborar los contratos y anexos que regulen las relaciones con los clientes, con claridad, en caracteres legibles a simple vista, y ponerlos a disposición de estos para su aceptación”, y agrega, "Copia de los documentos que soporten la relación contractual deberá estar a disposición del respectivo cliente, y contendrá los términos y condiciones del producto o servicio, los derechos 
y obligaciones, y las tasas de interés, precios o tarifas y la forma para determinarlos".

Es en esta última mención donde los términos y condiciones parecieran presentarse como una figura independiente, en alguna medida, de los contratos, reglamentos y otros acuerdos de los que surgen las relaciones contractuales en el sector financiero. ${ }^{9}$

Por otra parte, se debe poner de presente que la Superintendencia Financiera también impone el deber a las entidades vigiladas de "dejar evidencia documentada de que los clientes las han conocido y aceptado",10 refiriéndose a los términos y condiciones en que se presten los servicios tecnológicos de productos y servicios financieros y bursátiles en general.

Ahora bien, en cumplimiento de tal instrucción, sería necesaria la captura de información personal para la recolección de evidencia de la aceptación, pues, muy probablemente, dependiendo de la solución tecnológica implementada, podría ser necesario capturar la IP (internet protocol) o datos personales como el nombre, teléfono o claves para autenticarse y acceder a los portales transaccionales en donde se alojan los servicios electrónicos -cualquiera de los cuales se puede tomar como un dato sensible por su asociación

$9 \quad$ No olvidemos que, por la naturaleza técnica y financiera de la mayoría de los productos y servicios financieros, bursátiles y aseguradores, los términos y condiciones de los mismos son recogidos en reglamentos de productos, tal como ocurre con la administración de fondos de pensiones obligatorios o voluntarias y cesantías o de fondos de inversión colectiva, los cuales, por su extensión, deben ser entregados en forma independiente del formulario que los consumidores diligencian para vincularse al producto y a la entidad oferente del mismo. con los datos financieros-. Por lo tanto, también debe asegurarse, dentro de estos esquemas de configuración contractual, aspectos de información sensible y protección de datos asociados.

Paralelamente, la Ley 1480 de 2011, por medio de la cual se expide el Nuevo Estatuto de Protección al Consumidor, el cual aplica a consumidores diferentes de aquellos cobijados con normas especiales, como las previstas en la Ley 1328 de 2009, contiene otras referencias a términos y condiciones, como acuerdos autónomos e independientes, capaces de producir efectos jurídicos por sí mismos, diferentes de condiciones negociales generales y de los contratos de adhesión analizadas precedentemente.

Finalmente, dado que estos términos y condiciones, como figura contractual, carecen de consagración típica en la regulación colombiana -en estricto sentido-, surge de contera que su documentación es libre para acordar entre las partes o para imponer por una de estas, como ocurre en el sector objeto de análisis, sin perjuicio de las alusiones genéricas que hemos destacado en los apartados previos.

\section{Concepciones resultantes}

En general, encontramos que los términos y condiciones como son empleados hoy en día en la técnica jurídica colombiana, bien pueden referirse a los contratos o reglamentos de productos de entidades vigiladas como tal; o, por el contrario, pueden constituir documentos independientes cuando los mismos son creados para instrumentar relaciones puntuales del co- 
mercio moderno, e incluso los términos de uso de servicios adicionales que complementan los productos contratados.

Como se anotó, estos documentos de índole contractual son empleados hoy en día para regular el uso y navegación de sitios webs; para designar las reglas de promociones y/o rifas en las que se establecen los requisitos técnicos que deberá reunir el jugador para participar en el concurso y habilitarse como ganador de la misma, y, finalmente, en el sector financiero son especialmente aprovechados para la documentación de las condiciones de uso de servicios complementarios a la oferta tradicional de productos bancarios y bursátiles.

En la práctica, la regulación es altamente específica en cuanto a la designación y estructuración de los tipos contractuales que instrumentan los productos que constituyen el objeto social autorizado de las entidades vigiladas, no dejando mayor margen a la autonomía de la voluntad para completar o desarrollar los mismos, por el interés público que subyace a las actividades de captación y manejo de recursos del público.

Sin embargo, el desarrollo paralelo de nuevos canales para el ofrecimiento de los aludidos productos ha llevado, en franco aprovechamiento de los mecanismos, medios y tecnología actual -como la internet-, a la incursión en terrenos cuya regulación empieza apenas a florecer en la experiencia de sus primeros años de implementación, ejemplo de la cual es el capítulo XII.

En esa misma línea, las entidades financieras han llegado hasta internet para acortar la distan- cia física con un click de computador, en su cruzada por elevar, cada vez más, los estándares de servicio en beneficio del consumidor financiero.

Y es aquí donde, hasta antes de 2007, dichas relaciones negociales eran gobernadas, en su aspecto contractual, por la autonomía de la voluntad -matizada por el mismo interés público que es propio de la actividad bancaria y bursátil-, traducida en términos y condiciones que en muchos casos resultan ser adhesivos y abusivos, quedando el consumidor con la opción, bien de rechazarlos o de aceptarlos como se ha establecido; y esta realidad no ha cambiado mucho, pues, hoy en día, aun con la expedición del capítulo XII, los términos convencionales siguen sin ser estandarizados, recibiendo denominaciones diversas, tales como políticas de uso, reglamentos de uso, y en ocasiones contratos o simplemente términos y condiciones, con lo cual se deshomogeniza su naturaleza jurídica, sobre la cual no existe claridad actualmente, para lo cual se formulan las propuestas de los siguientes apartados.

\section{Acuerdo principal, ¿accesorio o coaligado?}

Planteada la anterior conclusión se analizará si los términos y condiciones son en sí mismos un acuerdo principal, o, por el contrario, accesorios; o, siendo principales, si se trata de un contrato coaligado con los contratos a través de los cuales se instrumentan los productos o servicios bancarios o de e-trading (Suescún Melo, 2005). 
Reza el artículo 1499 del Código Civil que "el contrato es principal cuando subsiste por sí mismo sin necesidad de otra convención, y accesorio, cuando tiene por objeto asegurar el cumplimiento de una obligación principal, de manera que no pueda subsistir sin ella".

Podría aseverarse que nos situamos frente a un contrato principal cuando hablamos de términos y condiciones, si los mismos no se refieren o vinculan a otros productos o servicios, sino que por el contrario regulan una relación o actividad específica e independiente.

La ilustración más patente podría verse en los términos y condiciones de uso de páginas webs, a los que el navegante se adhiere en más de una ocasión con el simple hecho de acceder al dominio respectivo.

Se diría lo opuesto, es decir, que nos hallamos frente a un contrato accesorio, cuando los términos y condiciones sirven para los fines de otro producto o servicio, sin el cual no subsistirían de forma autónoma.

Para esta hipótesis, la ilustración se puede ejemplificar en productos del sector bancario, como cuentas de ahorro, que tradicionalmente son gestionadas en oficinas y cajeros, pudiendo hoy en día también acudir a las oficinas virtuales de las entidades financieras, las que, en este caso, normalmente atan convencionalmente el producto financiero principal con el servicio complementario de herramientas tecnológicas, documentadas en términos y condiciones, al punto que, en muchas ocasiones, ${ }^{11}$ se indica expresamente que el mismo se incorpora al contrato, por ejemplo, de cuenta de ahorros o corriente del titular, con lo cual pareciera tomar fuerza la idea de que no se trata de una figura autónoma, sino que por el contrario perdería el objeto de su existencia si no estuviera alineado en torno al producto principal, del cual es una manifestación más.

Empero lo anterior, y buscando un punto intermedio entre la característica de principal o accesorio, podría preguntarse si tal vez se trata de contratos coaligados:

La coligación significa coordinación entre varios negocios jurídicos distintos para la ordenación de intereses que las partes pretenden atender y desarrollar. Dicho fenómeno presupone, entonces, dos o más contratos diferentes y un elemento de coligación jurídicamente relevante entre ellos. Un sector de la doctrina los llama "contratos recíprocos" o "contratos vinculados", y se explica que esa vinculación surge cuando se estipulan entre las mismas partes dos contratos en relación de dependencia mutua (interdependencia), en el sentido de que la ejecución o la validez del uno queda subordinada a la ejecución o la validez del otro. (Suescún Melo, 2005)

El autor en cita prosigue su análisis indicando que ambos contratos son autónomos entre sí, sin embargo, podría realmente afirmarse que, en Colombia, bien sea que se denominen tér-

Evidenciado en la revisión de sendos documentos de esta naturaleza. 
minos y condiciones, reglamentos o políticas de uso, ¿son estos contratos autónomos?

Analicemos la propuesta de la coligación y sus elementos, sin ahondar en sus ramificaciones: sin lugar a dudas, entre los contratos o reglamentos de productos de entidades vigiladas, y los términos y condiciones de uso de los canales de internet para el acceso a aquellos, existe una relación de vinculación incuestionable. Si no, ¿cuál sería la razón de ser de los términos y condiciones de canales de internet, si no hay un producto que gestionar por su intermedio?

En efecto, esta relación no presenta caracteres de ser inversamente relacional, por cuanto el producto de una entidad vigilada existiría y subsistiría por sí mismo siendo gestionado a través de los canales tradicionales de acceso ofrecidos por la entidad.

En este sentido, es menester concluir que, siendo los términos y condiciones de canales de internet un medio más para la operación de un producto de una entidad vigilada, sin el cual perfectamente este podría existir, nos hallamos frente a verdaderos contratos accesorios a los acuerdos, contratos o reglamentos de los productos cuya oferta complementan.

De hecho, la práctica contractual en el sector bancario, bursátil y asegurador ha propendido por asegurar, desde su texto, que los términos y condiciones de alguna forma se inserten o accedan, para formar un nuevo universo contractual complejo a los acuerdos, contratos o reglamentos de los productos tradicionales. Este buen sentido legal encuentra asidero en el Código Civil, y surge expresamente de la voluntad de los contrayentes en la medida en que la entidad vigilada así lo dispone en los términos y condiciones, y el consumidor financiero se adhiere a ellos en la forma prevista en dicho documento.

Con esta expresión de la voluntad contractual y la autonomía de las partes, se desvirtúa la teoría de coligación para el efecto que nos ocupa.

A pesar de esto, vale la pena analizar la postura de la Corte Suprema de Justicia en jurisprudencia de 1978 sobre la coligación o uniones de contratos, subdividiendo dicha figura en tres especies (Suescún Melo, 2005, p. 145):

(a) Simplemente externa: Ios distintos contratos tipos, independientes unos de otros, aparecen unidos externamente sin que haya subordinación de los unos respecto de los otros [...] (b) Con dependencia unilateral o bilateral: Ios distintos contratos tipos que aparecen unidos exteriormente son queridos como un todo. Se establece entre ellos una recíproca dependencia en el sentido de que el uno o los unos dependan del otro o de los otros, pero no al contrario. Tal expresión de los contratantes debe aparecer expresa o tácita. [...] (c) Alternativa: una condición enlaza los distintos contratos de forma que si el suceso positivo no acaece o si acaece el negativo, se entienda como concluido uno u otro contrato.

No obstante, de una relectura de la coligación con dependencia unilateral o bilateral podría surgir una posibilidad de dar independencia a los términos y condiciones de uso de canales de internet, considerando que se trata de acuerdos 
(el del producto y del canal) unidos y queridos como un todo por los contratantes, no obstante, tal unión y querer deberían ser vociferados claramente como expresión de la voluntad contractual, de lo contrario, no se cumplen los requisitos de tal categoría, tal y como ocurre en la mayoría de casos, en los cuales, como se indicó previamente, los términos y condiciones, reglamentos o políticas de uso de canales de internet para productos financieros, son insertados de forma expresa a los contratos de productos como extremidad accesoria de estos.

En este sentido, es claro que nos hallamos frente a verdaderos acuerdos de carácter accesorio, que no sobrevivirían en ausencia del acuerdo principal con el que se instrumenta el producto.

Igualmente, tal conclusión se puede extraer de forma tácita de la redacción del deber de documentación antes trascrito, conforme con el capítulo XII, el cual incluso los califica de compromisos, indicando que estos deberán establecer las condiciones bajo las cuales se prestarán los servicios por parte de las entidades vigiladas.

\section{E. El caso especial del enrutamiento de órdenes}

Diferente a lo analizado hasta este momento, el enrutamiento de órdenes, o e-trading, el cual constituye un acuerdo y un canal adicional para el desarrollo del contrato de comisión de valores basado en internet, tuvo la ventaja de ser envuelto en la forma de un contrato especial de prestación de servicios por designio de la Superintendencia Financiera de Colombia.
Reza el numeral primero del capítulo V, título IX, de la Circular Básica Jurídica de la Superintendencia Financiera de Colombia, que el Contrato de Ruteo Electrónico de Órdenes es el "acuerdo en virtud del cual una sociedad comisionista de bolsa de valores que es afiliado a un sistema de negociación de valores o miembro de una bolsa de valores, pone a disposición de sus clientes de contrato de comisión el envío o transmisión electrónica de sus órdenes a dichos sistemas $[\ldots] "$.

Considerando que el contrato de comisión mercantil común y corriente se estructura sobre las gestiones del comerciante experto en el marco de la comisión para compra y venta de valores, las órdenes del cliente se traducen en la instrucción para la compra y venta de valores en sistemas transaccionales que recibe y ejecuta el comisionista de valores, con sujeción a reglas conductuales y de asesoría, que varían según la naturaleza del cliente y los riesgos que comporten sus decisiones de inversión.

Igualmente, y con una perspectiva proteccionista, la Superintendencia dispone, en el numeral 5.1.9 del capítulo $V$ en comento, que las sociedades comisionistas de bolsa deben dar cumplimiento, en lo que resulte aplicable, a lo previsto en el capítulo XII, o demás normas que lo adicionen, sustituyan o modifiquen, y en particular a los numerales 3.2, 3.3, 4.9, 5 y 7 de dicho capítulo, con lo cual existe algún tipo de equivalencia tecnológica sin asimetrías regulatorias entre la instrumentación de estos canales, excepto por el hecho de que su documentación siguió el derrotero contractual con las mayores segu- 
ridades y claridad convencional que ello puede conllevar.

El capítulo en cita llega incluso a prescribir algunos contenidos para el Contrato de Ruteo Electrónico, cuando indica en su numeral 5.2.1.2, que este

[...] debe establecer como mínimo que el cliente está dispuesto a cumplir:

- con la normativa del mercado;

- los deberes y obligaciones establecidos en la regulación y;

- la reglamentación de los sistemas de negociación de valores y de las bolsas de valores.

Seguidamente, el numeral 5.5 establece el contenido completo del Contrato de Ruteo de Órdenes, entre los que se destacan el acuerdo sobre su objeto y los términos y definiciones, obligaciones especiales, entre otros.

Si bien el Contrato de Ruteo se muestra con el espectro propio de un contrato accesorio al de comisión para compra y venta de valores con una sociedad comisionista de bolsa, al estructurarse como contrato “[...] su modo de perfeccionamiento es consensual [...] adhiriéndose [...] el comitente [...] a las condiciones preestablecidas por el comisionista en el contrato estandarizado, aprobado previamente por la Superintendencia Financiera de Colombia" (Aguirre, 2012, p. 9).

Con lo anterior, no cabe duda de que el regulador revistió de una mayor seguridad jurídica a las relaciones creadas al albor del contrato de comisión y de ruteo, en claro desmedro de todas las demás operaciones económicas que se apalancan en términos y condiciones extremadamente básicos o incluso abusivos, aprovechando el espacio de maniobra amplio que genera la regulación tan parca para la operación en canales electrónicos de los demás productos bancarios y bursátiles, diferentes de la comisión para compra y venta de valores.

\section{F. Propuesta sobre la naturaleza jurídica de los términos y condiciones y conclusión}

Es viable señalar que los términos y condiciones, según la práctica jurídica actual, constituyen verdaderos acuerdos de voluntad de naturaleza adhesiva y dependiendo del entorno o utilidad del mismo a otros contratos o convenios, se podrá establecer si se trata de un contrato de carácter principal, o si por el contrario se trata de uno accesorio, en la medida en que vive y subsiste por razón de la existencia de otro acuerdo.

Creemos que, respecto del sector bancario y bursátil, los términos y condiciones, en la medida en que estén vinculados a un producto ofrecido por una entidad vigilada, son, como se indicó antes, de carácter accesorio.

La regulación de la Superintendencia Financiera debería migrar hacia una protección más clara del consumidor financiero, instruyendo de forma particular a sus entidades vigiladas sobre la necesidad de alinear las soluciones jurídicas actuales en anexos de los productos desde el 
inicio de la relación, de forma tal que se alcance algún grado de uniformidad en el ofrecimiento de los servicios basados en internet, considerando los riesgos inherentes a esta actividad y los posibles abusos a que se encuentran expuestos los consumidores ante la libertad de configuración contractual relativa de estos acuerdos que, como se indicó antes, adopta diversas y muy heterogéneas vestimentas convencionales, con connotaciones más o menos importantes, dependiendo de la redacción y profundidad por la que voluntariamente opte una entidad vigilada.

Esto por cuanto normalmente este tipo de documentos está diseñado para establecer algunas reglas; principalmente, identificar riesgos de operación de los canales, recomendar prácticas de uso seguro de los productos y servicios, y, sobre todo, establecer reglas de responsabilidad civil que normalmente excluyen la responsabilidad de la entidad vigilada ante eventos de fraude o pérdida de recursos.

En realidad, la mayoría de apartados de los que se componen estos términos y condiciones para uso de canales de internet surgen de normas especiales y desarticuladas entre sí por causa de la dispersión y explosión regulatoria propia de nuestro sistema, que luego es amalgamada por la autonomía de la voluntad privada en este tipo de documentos.

El amplio campo de manejo legal que se completa con los designios de la autonomía de la voluntad privada, se cierra con importantes normas sobre responsabilidad civil que analizaremos en el siguiente apartado.

\section{PERSPECTIVA DE RESPONSABILIDAD CIVIL}

Conocidos como son los elementos de la responsabilidad civil, analizaremos cada uno en sede de la regulación especial del sector bancario y bursátil, anotando las conclusiones respecto de cada uno, y seguidamente pasaremos a revisar la experiencia de la Superintendencia Financiera en los fallos expedidos con fundamento en sus facultades jurisdiccionales, reservando para el final el análisis del hecho dañoso en función de los deberes jurídicos de que son garantes las entidades vigiladas y sus consumidores financieros:

\section{A. Imputabilidad}

Se refiere, en términos generales, al factor subjetivo de la responsabilidad, es decir, al sujeto a quien puede endilgársele en este caso la autoría o fuente del hecho dañoso.

\section{B. Daño}

En sede de los posibles daños que pueda afrontar de ordinario un consumidor financiero, parte débil de la relación contractual, los resultados normalmente se centran en pérdidas de recursos por transacciones fraudulentas, denegación de servicio, fallas en los equipos o programas, entre otros. 


\section{Relación de causalidad}

Naturalmente que sin vínculo de causalidad entre los diversos elementos de la responsabilidad, esta no se configurará.

\section{Hecho dañoso}

Si partimos de la premisa de que el daño deviene de la "infracción a un deber jurídico", como enseña el maestro Paucar, resulta crucial entender cuáles son los deberes de uno y otro extremo de la relación contractual bajo la regulación especial y dispersa que gobierna esta figura contractual en análisis:

\section{E. Deberes jurídicos de fuente legal a cargo de las entidades vigiladas}

La Ley 1328 de 2009 establece como obligaciones especiales de las entidades vigiladas: ${ }^{12}$

- Entregar el producto o prestar el servicio debidamente [...] y emplear adecuados estándares de seguridad y calidad en el suministro de los mismos.

- Elaborar los contratos y anexos que regulen las relaciones con los clientes, con claridad, en caracteres legibles a simple vista, y ponerlos a disposición de estos para su aceptación. Copia de los documentos que soporten la relación contractual deberá estar a disposición del respectivo cliente, y contendrá los términos y condiciones del producto o servicio [...].

12 Artículo 7 de la Ley 1328 de 2009.
- Disponer de los medios electrónicos y controles idóneos para brindar eficiente seguridad a las transacciones, [...] y a las redes que la contengan.

- [...] Informar a los consumidores financieros, como mínimo, las características de los productos o servicios, los derechos y obligaciones [...] las medidas para el manejo seguro del producto o servicio [...].

Así mismo, prohíbe la inclusión de cláusulas abusivas en contratos de adhesión y califica de prohibidas algunas prácticas, siendo de las más relevantes para este análisis "la inversión de la carga de la prueba en caso de fraudes en contra del consumidor financiero", ${ }^{13}$ la cual se encuentra prohibida como cláusula y práctica simultáneamente, considerando la complicada historia detrás de las pugnas con las entidades vigiladas en eventos de fraude o malversación.

La norma en comento facultó igualmente a la Superintendencia Financiera para calificar de forma previa situaciones que pudieran constituir cualquiera de las categorías anteriores, traduciéndose esta facultad en el capítulo XVI, título I, de la Circular Básica Jurídica de este organismo, en el que se indica que las entidades vigiladas deberán informar al consumidor, entre otros, las "recomendaciones de seguridad para la realización de operaciones".

Igualmente, el numeral 10.1 del capítulo XVI califica de abusivas las cláusulas contractuales que "obligan al consumidor financiero a certifi-

13 Artículos 11 y 12 de la Ley 1328 de 2009. 
car que se encuentra en un computador seguro". De usanza en la mayoría, si no en todos los términos y condiciones de entidades vigiladas con oferta de servicios tecnológicos, hoy en día no podrá emplearse como requerimiento exigible al consumidor.

Igualmente, califica de abusiva cualquier cláusula que haga "que el consumidor financiero asuma toda responsabilidad por cualquier operación realizada con la clave asignada, cuando el perjuicio a que haya lugar sea consecuencia del mal uso de la misma por parte de la entidad vigilada".

En este mismo sentido, se consideran abusivas las cláusulas que "expresen que la entidad no se hace responsable por los virus, programas fraudulentos o cualquier exposición no autorizada o ilícita del servicio que de cualquier manera pueda afectar la confidencialidad o integridad de la información presentada", y "las que eximen de todo tipo de responsabilidad a la entidad vigilada por los errores u omisiones de cualquier clase que puedan producirse en la realización de las operaciones".

Finalmente, y en punto a los deberes frente a la seguridad de la información en canales como internet, el capítulo XII estableció las siguientes obligaciones a cargo de las entidades vigiladas, así:

\subsection{Divulgación de información}

3.4.4 Informar adecuadamente a los clientes respecto de las medidas de seguridad que deberán tener en cuenta para la realización de operaciones por cada canal [...].
3.4.5 Establecer y publicar por los canales de distribución, en los que sea posible, las medidas de seguridad que deberá adoptar el cliente para el uso de los mismos.

3.4.6 Diseñar procedimientos para dar a conocer a los clientes, usuarios y funcionarios los riesgos derivados del uso de los diferentes canales e instrumentos para la realización de operaciones.

\section{F. Deberes jurídicos de fuente legal a cargo de los consumidores financieros}

La regulación, igualmente, impone, en algún grado, un principio de responsabilidad a los consumidores financieros que, como se enseñó anteriormente, sugiere como práctica de autoprotección a cargo del consumidor financiero, entre otras:

c) Observar las instrucciones y recomendaciones que imparta la entidad vigilada sobre el manejo de productos o servicios financieros.

d) Revisar los términos y condiciones del respectivo contrato y sus anexos, así como conservar las copias que se le suministren de dichos documentos.

Al margen de lo anterior, como se advirtió, la Ley 1328 de 2009 consagra una excepción a las prácticas de autoprotección del consumidor financiero que tolera que incluso ante la omisión de la debida diligencia mínima del consumidor, esto no exima del cumplimiento de sus obligaciones a la entidad vigilada.

La exposición de motivos de la Ley 1328 de 2009, al abordar las prácticas de protección 
propia, llega incluso a calificarlas de buenas prácticas, restándole bastante importancia ejecutiva a la mismas. A pesar de esto, no pareciera que la citada ley buscara modificar las reglas actuales de responsabilidad civil, su interpretación o aplicación.

Tal situación se refrenda en sentencias expedidas por la Superintendencia Financiera de Colombia ${ }^{14}$ en la que tutela y pondera el cumplimiento de estos deberes a la hora de impartir justicia en sede de sus excepcionales facultades.

No obstante, antes de ahondar en este concepto, es menester poner de presente la tendencia de responsabilidad aplicable a las instituciones financieras, que se resume en el siguiente extracto de sentencia que ejemplifica la situación:

[...] las instituciones financieras, y particularmente las bancarias, están sujetas a un especial régimen de responsabilidad civil frente a los daños que puedan sufrir los clientes o usuarios de sus servicios, el que ha estado presidido, entre otros, por lineamientos tales como que dichos establecimientos son empresarios profesionales que se consideran expertos en la intermediación financiera; que reciben una especial habilitación del Estado para desarrollar su actividad en virtud de la confianza que se deposita en ellos al conferirles la posibilidad de manejar el ahorro del público, por lo que surgen a su cargo especiales deberes de diligencia; que en las operaciones de captación de recursos ordinariamente celebran contratos de depósito irregular en los que el banco se

14 En desarrollo de las facultades jurisdiccionales que le han sido atribuidas. convierte en titular de los recursos transferidos y asume, por ende, obligaciones de resultado para efectos de su restitución; y, finalmente, que en su labor deben administrar diversos riesgos (de falsificación de títulos, de indebidas intromisiones informáticas, etc.) respecto de los cuales no es admisible su traslado sin formula de juicio a los ahorradores o cuentahabientes, menos aún a través de estipulaciones contractuales que contengan exoneraciones totales de responsabilidad que el ordenamiento aplicable proscribe expresamente (art. 98, num. 4.1, inc. $2^{\circ}$, del Estatuto Orgánico del Sistema Financiero) y que la jurisprudencia igualmente ha censurado. ${ }^{15}$

Una vez establecida la especial exigencia de diligencia a cargo de las entidades vigiladas en el ofrecimiento de sus productos, analizaremos dos fallos en que la Superintendencia ha valorado el cumplimiento de deberes a cargo del consumidor financiero como elemento determinante de la ausencia de responsabilidad en la entidad vigilada:

- Expediente Superintendencia Financiera No. 2013015100

Radicado 20130063

En contra de cualquier fallo predecible, la Superintendencia declaró libre de responsabilidad a una entidad vigilada sin identificar, aduciendo encontrarse probado en el proceso que el consumidor financiero reclamante no observó los deberes ni obligaciones derivados de su vinculación a los términos y condiciones del servicio

15 Sala de Casación Civil de la Corte Suprema de Justicia (expediente 2010-00320-00) en sentencia de tutela del 11 de marzo de 2010. 
de transacciones en línea de la entidad vigilada; en efecto, señaló la Superintendencia que

encuentra acreditado que el demandante [...] no cambiaba su clave regularmente y que accedía al sitio web del banco a través de buscadores, como Google, en contravía de las indicaciones recibidas de la entidad demandada de digitar directamente la dirección www.XXXX. com, contenida en el documento de las políticas de seguridad para transar por internet [...] lo que conllevó a situarse en una posición de riesgo evidente para que terceras personas accedieran a su información personal para el ingreso a su cuenta y con ello a disponer de los dineros depositados, incumpliendo con ello sus obligaciones.

Diáfanamente y con un sentido de clara justicia, la Superintendencia tuteló el cumplimiento de deberes y obligaciones surgidos, en este caso, del documento denominado "Políticas de seguridad para transar por internet", en el que se incluían las diversas recomendaciones de uso seguro que la entidad financiera realizaba respecto del uso de estos canales.

- Expediente Superintendencia Financiera No. 2013023470

Radicado 2013-0099

En este caso, de nuevo arremete la Superintendencia contra la negligencia con que los consumidores financieros manejan sus recursos informáticos.

En efecto, en esta litis el actor reclamaba de la entidad vigilada la devolución de una cifra determinada correspondiente a retiros aparente- mente fraudulentos con la clave del consumidor a través de argucias que el mismo consumidor inadvertidamente permitió al no observar las medidas de seguridad recomendadas por la entidad vigilada.

Argumenta la Superintendencia que

[...] aunque la responsabilidad que se predica de las entidades financieras se analiza bajo la perspectiva de la anunciada diligencia y profesionalismo que se impone a aquellas en el ejercicio de su actividad, no lo es menos que esta puede desaparecer o verse menguada atendiendo a la participación excluyente o concurrente del consumidor financiero en la causación del daño cuya indemnización se persigue. ${ }^{16}$

Con esta postura queda contundentemente refrendado que el incumplimiento de deberes y prácticas de protección, por cualquiera de los extremos de la relación contractual, no desestima la configuración de responsabilidad a cargo de quien repudia la observancia de los deberes a su cargo.

Continúa discurriendo la Superintendencia:

En efecto, si bien el ejercicio de la actividad financiera genera un régimen especial de responsabilidad en sus relaciones contractuales, lo anterior no significa que el consumidor financiero esté autorizado, ni le sea permitido, incumplir, descuidar, desatender o desconocer las obligaciones que paralelamente le asisten,

16 Expediente Superintendencia Financiera 2013023470. Radicado 2013-0099. Recuperado de www.superfinanciera .gov.co 
máxime que aquello que se encuentra en juego es su propio patrimonio. ${ }^{17}$

Así las cosas, encontramos que, si bien el consumidor financiero es merecedor de la protección especial por la que tanto se ha abogado a lo largo de este documento, las fallas en el cumplimiento de sus deberes jurídicos moldean las consecuencias económicas de su actuar, ejemplificando la necesidad de expedirse instrucciones exactas que impriman un tinte legalista a los términos y condiciones de uso de canales informáticos, sin los cuales no se genera una auténtica preocupación por parte del consumidor o de la entidad vigilada de implementar dicho acuerdo y respetarlos al punto que se vuelven nugatorios por su presentación en un vehículo convencional que, en la mente de una persona no versada en leyes, será un documento más de la papelería formal que acompaña a los contratos de productos o servicios.

\section{CONCLUSIONES}

¿Son los "términos y condiciones" documentos con la entidad contractual suficientes para gobernar las relaciones de los consumidores con sus entidades financieras en el marco de la prestación de servicios adicionales como los basados en internet? En nuestra opinión la respuesta claramente es no.

La regulación debería indicar expresamente que tales documentos deben ser elaborados en for-

17 Expediente Superintendencia Financiera 2013023470. Radicado 2013-0099. Recuperado de www.superfinanciera .gov.co ma independiente del producto al que accede, pero en todo caso incorporado al mismo para que no sea esto designio libre de una entidad vigilada, pudiendo presentarse toda clase de abusos respecto de los clientes considerando el carácter de adhesivo de la mayoría de contratos y acuerdos por medio de los que se instrumentalizan estos productos.

Esa regulación propuesta debe prevenir que, como en los fallos analizados, se presente una mayor incidencia de responsabilidad que recaiga sobre los consumidores, quienes, ignorantes de las implicaciones jurídicas de adherirse a términos y condiciones, sufran las consecuencias de esta falta de estructura y definición legal.

La generalidad de la solución no debe entenderse en contravía de la neutralidad competitiva ${ }^{18}$ (Carbajales, 2006), pues a pesar de las diferencias entre los productos de unas y otras entidades vigiladas, bien bancarios o de e-trading, esta llevaría a que los términos y condiciones funjan como una ventaja en favor del consumidor financiero considerando que, si los riesgos técnicos y contractuales son transversales al canal de internet, la solución regulatoria debería ser idéntica respecto de todas las entidades vigiladas, con lo cual se dejaría en pie de igualdad a los consumidores de esta relación desigual.

No consideramos que la solución deba ser tan elaborada como la proveída respecto del ruteo de órdenes, sin embargo, la regulación debe

18 Situación generada por regulación general que no consulta con la naturaleza o condiciones específicas de las instituciones de un mercado financiero o de valores. 
ser clara y contundente para evitar que se presenten abusos y atropellos a la hora de ejercer derechos en el marco de fraudes, incumplimientos y otros eventos con capacidad de afectar el patrimonio de los consumidores financieros, últimos destinatarios de las normas en análisis.

Finalmente, las instrucciones de la Superintendencia Financiera en relación con educación financiera ${ }^{19}$ como estrategia de protección al consumidor debería propender por profundizar la conciencia del consumidor sobre sus responsabilidades frente a los contratos que suscribe, como mínima expresión de su debida diligencia, al paso que desarrollara estrategias que permitieran disminuir la complejidad de las estructuras contractuales empleadas de forma que su contenido y presentación sea más amable para consumidores que no siempre están versados en estas ciencias.

\section{Referencias}

Aguirre Soriano, D. (2012). Medios probatorios de la responsabilidad civil en materia de canal e-trading. Revista de Derecho Privado (48), 9.

Arrubla Paucar, J. (2008). Contratos Mercantiles. Tomo III (7. a ed.). Biblioteca Jurídica Diké.

Azuero, S. (2011). Contratos Bancarios. Su significación en América Latina (6. ${ }^{a}$ ed.). Bogotá: Legis.

19 Prevista como un derecho de los consumidores en la Ley 1328 de 2009.
Carbajales, M. (2006). La regulación del mercado financiero. Hacia la autorregulación del Mercado de Valores. Madrid: Marcial Pons.

Corte Suprema de Justicia. Sala de Casación Civil. Expediente 2010-00320-00. Sentencia de tutela del 11 de marzo de 2010.

Cotino, L. (2008). Consumidores y usuarios ante las nuevas tecnologías. Valencia: Tirant Lo Blanch.

Díaz Orjuela, L. (1999). Banca en Internet. Un nuevo estilo de servicio. Tendencias tecnológicas del sector financiero para el siglo XXI. Asobancaria.

En Colombia las cifras de delitos informáticos van en aumento. El País. Recuperado de http://www.elpais.com.co/elpais/judicial/ noticias/colombia-cifras-delitos-informaticos-van-aumento

Ecija Abogados (2010). Compliance. Cumplimiento normativo y seguridad en la empresa. Barcelona: Aranzadi.

Farina, J. (2011). Defensa del consumidor y del usuario. Buenos Aires: Astrea.

Gersovich, C. (2011). Consumidores Bancarios. Derechos económicos de los bancos y sus clientes. Buenos Aires: Abeledo Perrot.

Miranda, L. y Pagador, J. (2012). Derecho (Privado) de los consumidores. Madrid: Marcial Pons. 
Normativa Presidencia. Gobierno en Línea. Recuperado de http://wsp.presidencia.gov.co/ Normativa/DAPRE/Paginas/GobiernoEnLinea.aspx

Rico, M. (2007). Derecho de las nuevas tecnologías. Buenos Aires: La Roca.

Robles, J. F. (1998). Prácticas incorrectas y condiciones abusivas en las operaciones bancarias. Madrid: Instituto Superior de Técnicas y Prácticas Bancarias.

Rustad, M. L. y Onufrio, M. V. (2012). Reconceptualizing Consumer Terms of Use for a Globalized Knowledge Economy. University of Pennsylvania Journal of Business Law, 14, 1085; Suffolk University Law School Research Paper, 12-30, recuperado de http:// ssrn.com/abstract=2123599
Suescún Melo, J. (2005). Derecho Privado. Estudios de derecho civil y comercial contemporáneo. Tomo II (2. a ed.). Bogotá: Legis.

Superintendencia Financiera de Colombia. Cuenta corriente o de ahorros - Extractos Estado de cuentas - Contrato de adhesión. Concepto 2007001302-001 del 23 de febrero de 2007. Recuperado de https://www. superfinanciera.gov.co/SFCant/Normativa/ Conceptos2007/2007001302.pdf

Terms of service. Wikipedia. Recuperado de http://en.wikipedia.org/wiki/Terms_of_service

Zapata, F. (2001). Sociedad del conocimiento y nuevas tecnologías. Revista de Derecho Privado, (26). 